\title{
Delayed Encephalopathy Following Carbon Monoxide Intoxication
}

\author{
G.M. SAWA, C.P.N. WATSON, K. TERBRUGGE, M. CHIU
}

SUMMARY: The case history and CT scan of a patient with delayed encephalopathy following carbon monoxide intoxication are described. The patient recovered.

The CT scan revealed symmetrical areas of decreased density at the level of the globus pallidus. This case differs in several ways from other cases of carbon monoxide intoxication in which abnormalities of the CT scan were found.

RÉSUMÉ: Nous décrivons l'histoire de cas et la tomodensitométrie d'un patient avec encéphalopathie tardive consécutive à une intoxication au monoxide de carbone, mais dont le patient a récupéré.

La tomodensitométrie révéla des zones de densité diminuée au niveau du globus pallidus. Ce cas diffère des autres publiés où l'intoxication au monoxide de carbone s'accompagnait d'anomalies différentes à la tomodensitométrie.

From the Departments of Medicine (Neurology), Mississauga Hospital; and Radiology, Toronto Western Hospital.

Reprint requests to Dr. G. Sawa, 3025 Hurontario Street, Suite 505, Mississauga, Ontario, L5A $2 \mathrm{H} 7$, Canada.

\section{INTRODUCTION}

The clinical and pathological findings in patients with neurological involvement from carbon monoxide intoxication (COI) have been well documented (Courville, 1957; Garland \& Pearce, 1967; and Bour \& Ledingham, 1967). Acute encephalopathy, coma and death may ensue. Residual complications include dementia, delayed encephalopathy, seizures, athetosis, Parkinsonism, psychosis (Garland \& Pearce, 1967) and a peripheral neuropathy (Snyder, 1970).

Delayed encephalopathy following COI is rare (Bour \& Ledingham, 1967; Plum \& Posner, 1962, and Gordon, 1965). The prognosis in this condition is unknown.

The purpose of this paper is to relate the case history of a woman with delayed encephalopathy, and to report the CT scan findings, which correlate with some of the pathological features in this condition.

\section{CASE REPORT}

This 52 year old female received an accidental 12 hour exposure to carbon monoxide poisoning on January 25, 1979. Her initial carboxy-hemoglobin level was only $6.5 \%$ but this was drawn after she had been given high flow oxygen for $1 \frac{1 / 2}{2}$ hours. The husband and son had been exposed to the carbon monoxide poisoning for a shorter period and clinically were less severely involved and their carboxy-hemoglobin levels were $23 \%$ each

Initially, she was drowsy and responded appropriately to pain, but was unable to talk. She had bilateral upgoing toes and diffuse hyperreflexia. Her complexion was cherry pink.

Her initial hospital course was complicated by a mild adult respiratory distress syndrome. She developed bilateral pulmonary infiltrates and transient mild hypoxemia which was vigorously treated.

She was discharged from hospital 7 days after the intoxication and her husband and friends felt that her "sparkle had gone" but she was otherwise normal mentally.

At 14 days post COI she became listless, apathetic and withdrawn and a definite impairment of memory was noted. At 24 days post $\mathrm{COI}$ she became disoriented and had a more severe impairment of memory involving recent and past events. She would sit and stare for long periods and did not seem to know what to do with herself. She became clumsy and had difficulty doing simple tasks such as dancing which previously had given her no trouble. She began to have trouble with simple arithmetic, dividing the food up amongst the family members, and playing cards.

She was first examined neurologically at 28 days post COI. She denied any problems with her memory and lacked insight into her illness. General examination was normal. Neurological examination revealed masked facies with a flat and often inappropriate affect. She was oriented to her name and place, but she did not know the exact date. Her responses were slow, she could remember recent events in the news, but did not remember clearly her recent illness. Her parables were concrete and she had trouble with serial 7's. Her general knowledge was patchy and out of keeping with her knowledge prior to her illness. She could follow simple, but not complicated commands. She could read simple sentences, draw, and write normally. There was a questionable weakness of the left arm and leg and mild bilateral intention tremors in the arms were noted.

There was continued deterioration in her mental status and she became almost helpless in self care and had to be told what to order for her meals and later required assistance with feeding. She would put inedible objects in her mouth and spill her food tray if left unattended. There was marked perseveration of motor activities.

At 35 days post $\mathrm{COI}$, she had become incontinent of urine. She could no longer write her name and there was evidence of an aphasia, constructural apraxia and a positive snout and bilateral grasp reflexes were noted. There was some cogwheel rigidity noted in the left arm which was an evanescent sign. Decreased rapid alterna- 
ting movements were noted in the left arm as well. The reflexes in the legs were brisker than the arms. By 40 days post COI, she was unable to follow even simple commands and the degree of apraxia in writing and construction as well as the motor perseveration was more marked. After this her condition stabilized and there was no further deterioration.

Formal neuropsychological testing was performed. This revealed evidence of severe multifocal bilateral impairment of cerebral function. She was unable to carry out the routine neuropsychological tests that were available.

Her initial EEG at 29 days post COI revealed diffuse delta activity with frontal predominance. No periodic complexes were recorded. Serial EEG's revealed gradual improvement in the EEG and by day 103 post COI the EEG had returned to normal. The spinal fluid was normal. Cerebral angiograms were normal.

Her first CT scan at 34 days post COI (Figure IA, arrows) revealed two small, well defined rounded areas of decreased density approximately at the level of the globus pallidus. There was no enhancement with contrast. No mass effect was associated with these lesions. Mild to moderate diffuse cerebral atrophy was present.

The CT scan four weeks after the initial examination showed no change.

Clinically, recovery was gradual, but
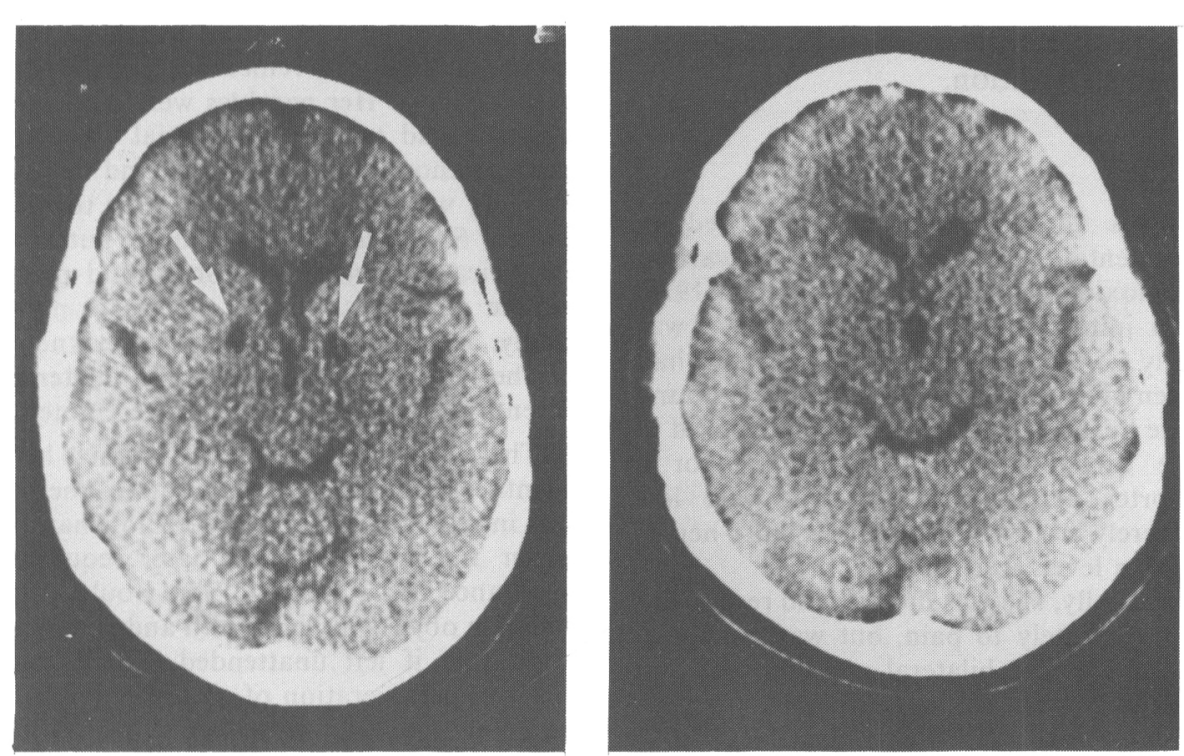

Figure 1A: (Left) Nonenhanced CT scan shows small rounded areas of decreased density approximately at the level of the globus pallidus (arrows).

Figure IB: (Right) Nonenhanced CT scan nine months after the initial examination shows localized widening of the third ventricle, but the lesions at the level of the globus pallidus can no longer be identified with certainty.

dramatic. By 47 days post COI, noticeable improvement was observed. Her neurological examination was then normal except for abnormalities of higher mental function. She began to write and behave normally after this date.

Neuropsychological tests at day 78 post COI revealed mild residual abnormalities suggesting dysfunction of frontal lobes as well as a right temporal lobe. However, she was able to perform the entire battery of neuropsychological tests on this occasion. She scored in the average range on all the subtests of the Weschler Adult Intelligence Scale.

She was discharged from hospital by day 105 post COI. She was able to care for herself and gradually resumed all her previous activities such as dancing and driving a car, etc

Neuropsychological testing at 9 months post COI revealed some further improvement of mental functioning, with mild difficulties in concentration and tasks requiring rapid decisions.

$A$ repeat CT scan (Figure $1 B$ ) 10 months after the initial examination showed mild enlargement of the anterior aspect of the third ventricle. The previously demonstrated lesions at the level of the globus pallidus on both sides could no longer be identified with certainty. Moderate cortical cerebral atrophy was again noted. Localized widening of the third ventricle supported the contention of a localized atrophic phenomenom at that level

When last seen at 11 months post $\mathrm{COI}$, she was functioning well. Her only complaint was she had slowed down somewhat in general. Her neurological examination was normal.

\section{DISCUSSION}

Although a delayed encephalopathy following $\mathrm{COI}$ is not unique to this form of hypoxia, (Plum \& Posner, 1962; Richardson \& Chambers, 1959; Ginsberg \& Hedley-Whyte, 1976; and Dooling \& Richardson, 1976) it is perhaps the best known etiological factor. The possibility of recovery has not been emphasized in the literature although Richardson \& Chambers, (1959, Case 3 ) described such a case.

The pathological findings in cases of fatal COI include both patchy and widespead areas of demyelination (Courville, 1957) as well as necrosis of the globus pallidus. In addition, there is laminar necrosis of the cerebral cortex and hypoxic changes in the neurons of the hippocampus and cerebellum (Bour \& Ledingham, 1967 and Greenfield, 1976.)

Nardazzi (1979) reported a patient who presented in coma following COI. The patient recovered with residual memory deficits. The enhanced CT scan revealed areas of increased uptake of contrast in the area of the basal ganglia and dentate nucleus of the cerebellum.

Sawada \& Ohashi (1980) reported 21 patients with acute COI. In 11 of their patients, areas of low density were seen bilaterally in the globus pallidus. These abnormalities persisted after 3 months. The outcome was poor in 10 of these 11 patients. Clinical details regarding these particular cases were lacking and no mention was made of whether or not any of these patients had a delayed encephalopathy following $\mathrm{COI}$.

Although the CT scan in our case was similar to the 11 cases reported by Sawada \& Ohashi (1980), the present case is the first report of a delayed encephalopathy following COI with these particular CT scan abnormalities. Moreover, our case differs from the experience of Sawada \& Ohashi (1980), not only in that the patient recovered completely, but also that this recovery was associated with 


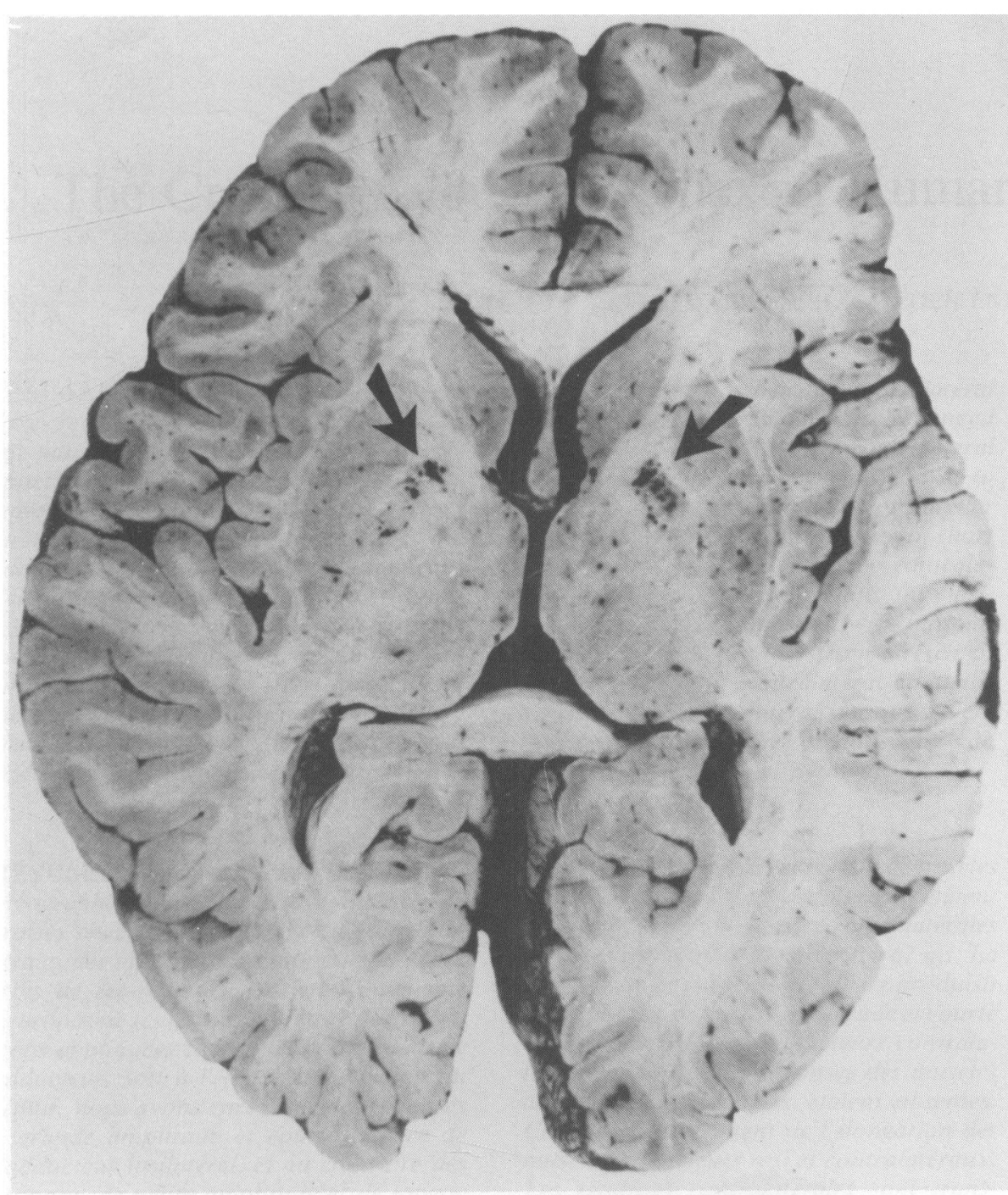

Figure 2: Horizontal section of brain at the level of the third ventricle demonstrating necrosis of globus pallidus bilaterally (arrows). (Reprinted with permission, Richardson, J.C. et al, Encephalopathies of Anoxia and Hypoglycemia. Archives of Neurology 1:70-82 1959. "Copyright 1959. American Medical Association")

apparent resolution of the low density lesions in the globus pallidus.

In addition, the findings in our case of symmetrical lesions in the area of the globus pallidus correlate well with an autopsy-proven case of fatal COI previously reported by Richardson \& Chambers (1959). In that case, symmetrical areas of necrosis involving the globus pallidus were demonstrated at autopsy (Figure 2, arrows).

The reason for the involvement of the globus pallidus following $\mathrm{COI}$ and other causes of hypoxia remain unknown.
In conclusion, this report is the first description of the CT scan appearance of a patient with delayed encephalopathy following COI. Moreover, the CT scan findings correlate with the reported pathological finding of involvement of the globus pallidus. This appearance on CT scan may help to corroborate the diagnostic impression of a delayed encephalopathy following hypoxia from COI. Its prognostic significance is unknown, but it is suggested that serial $\mathrm{CT}$ scanning should be done in such cases in order to ascertain whether or not resolution of these lesions will occur. Although Sawada \& Ohashi (1980) suggested that the presence of these lesions may carry a poor prognosis, this is not the experience in our case. Whether such patients will subsequently develop Parkinson features remains unknown.

\section{ACKNOWLEDGEMENTS}

The authors wish to thank Dr. G. Snow, Ph.D., Dept. of Psychology, Toronto Western Hospital, for performing the psychological tests in this case.

\section{REFERENCES}

BOUR, H. and LEDINGHAM, I. McA. (1967) Carbon Monoxide Intoxication Progress in Brain Research. 24: 1-203.

COURVILLE, C.B. (1957) The Process of Demyelination in the Central Nervous System. IV Demyelination as a Delayed Residual of Carbon Monoxide Asphyxia. Journal of Nervous \& Mental Disease. 125: 534-546.

DOOLING, E.C. and RICHARDSON, E.P. (1976) Delayed encephalopathy after Strangling. Archives of Neurology 33: 196-199.

GARLAND, H., and PEARCE, J. (1967) Neurological Complication of Carbon Monoxide Poisoning. Quarterly Journal of Medicine (New Series) 36: 445-455.

GINSBERG, M., HEDLEY-WHYTE, T., RICHARDSON, E.P. (1976) Hypoxic-Ischemic Leukoencephalopathy in Man. Archives of Neurology 33: 5-14.

GORDON, E.B. (1965) Carbon-monoxide Encephalopathy. British Medical Journal 1: 1232.

GREENFIELD'S NEUROPATHOLOGY (1976) Edited by Blackwood, W., and Corsellis, S.A.W. Year Book Medical Publishers, Chicago, pp 68-71.

NARDAZZI, L.R. (1979) Computerized Tomographic Correlate of Carbon Monoxide Poisoning. Archives of Neurology, 36: 38-39.

PLUM, F., POSNER, J. and HAIN, R.F. (1962) Delayed Neurological Deterioration after Anoxia Archives of Internal Medicine 110: 56-63.

SAWADA and OHASHI, et al (1980) Computerized tomography as an indication of longterm outcome after acute carbon monoxide poisoning. Lancet 1: 783-4.

SNYDER, R. (1970) Carbon Monoxide Intoxication with Peripheral Neuropathy. Neurology 20: $177-180$.

\section{ADDENDUM}

Since the preparation and acceptance of this manuscript, Kim, K.S., et al, have published a report in which 9 patients with acute carbon monoxide poisoning had CT scan abnormalities similar to that presented in this paper. None of these patients presented with a delayed encephalopathy as was the case in this paper.

Acute Carbon Monoxide Poisoning: Computed Tomography of the Brain. The American Journal of Neuroradiology, Volume 1. page 399-402, 1980. 